\title{
Emergence of Movie Stream Challenges Traditional DVD Movie Rental-An Empirical Study with a User Focus
}

\author{
Chiang-nan $\mathrm{Chao}^{1} \&$ Saibei Zhao ${ }^{2}$ \\ ${ }^{1}$ Tobin College of Business, St. John's University, New York, USA \\ ${ }^{2}$ University of New Brunswick, New Brunswick, Canada \\ Correspondence: Chiang-nan Chao, St. John’s University, New York, USA. E-mail: chaoc@stjohns.edu \\ Received: March 13, 2013 \\ Accepted: April 12, $2013 \quad$ Online Published: May 12, 2013 \\ doi:10.5430/ijba.v4n3p22 \\ URL: http://dx.doi.org/10.5430/ijba.v4n3p22
}

\begin{abstract}
Traditional movie DVD rental model has been challenged by a new business model of movie stream. Movie stream possesses convincing advantages over the traditional DVD rental. E-commerce shows a trend in the movie industry that consumers can stream comparable quality movies and TV shows directly from the Internet instead of waiting for the DVDs in the mail. Thanks to global technology advancement, movie stream has already prevailed. This study focuses on consumers' preferences of decision making variables for streaming movie from the Internet and the traditional DVD movie rental. The results indicate that consumers are shifting from DVD movie rental to movie stream, while home entertainment industry needs to improve both in technology and customer service. The consumers favor movie streaming and make it better competing with other ways of watching movie. The quality of movie stream and renting DVD disks may be less important for movie viewers. Movie industry should make movie stream easy to watch.
\end{abstract}

Keywords: e-commerce, movie stream, streaming, movie download, movie rental, DVD rental

\section{Introduction}

The competition for viewers in the movie industry takes many different forms. Traditional movie theaters, with high quality pictures on large screens and high quality sound effects, need the patrons show up physically; movie rental stores or movie rental websites, which provide the convenience for the customers to obtain DVD disks and watch movies on TVs at home; while movie stream via high speed internet connections, which is emerging as a new way that enables viewers watch movies without going to theaters, nor going to rental stores, nor placing DVD orders on websites, nor waiting for DVD disks (including Blue Ray DVD) to show up in the mail boxes, nor returning these disks to rental stores (Wingfield, 2010; Stone, 2010).

\subsection{Advancement of Technology in Computer Technology and Network}

This emerging phenomenon of movie stream depends heavily on the technology advancement in computers, networking, and most of all the speed and capacity of the internet. The monthly video internet traffic in 2013 will reach to 24,969 petabytes per month, an amazing 20 folds of the video traffic volume in 2008, about an equivalent of about 300 million DVDs crossing the network each month (Cisco, 2012). What impacts of this shift will have on businesses and consumers are of great interests. This study aims to explore only some of the impacts of the emerging movie stream in home entertainment industry, and to compare with traditional DVD movie rental.

Video consumption and distribution has witnessed a double digit growth in the past few years, converting and preparing this content for the digital realm was largely a 'black art' until recently, when several enterprise-grade solutions came onto the market. Video-related transactions grew from 12.4 percent of the total IP traffic in 2008 to approximately 39 percent total IP traffic in 2012, or are about twelve folds of the total volume excluding the amount of video exchanged through P2P file sharing. Internet video is predicted a 34 percent compound annual growth rate (CAGR) from 2011 through 2016. Internet video traffic will increase more rapidly than general consumer Internet traffic. The trends of on-demand viewing and high-definition video are generating very rapid growth in cable video and IPTV traffic transported over IP in metropolitan areas (Cisco, 2012). Figures 1 presents the monthly internet video traffic trend between 2008 and 2016. 


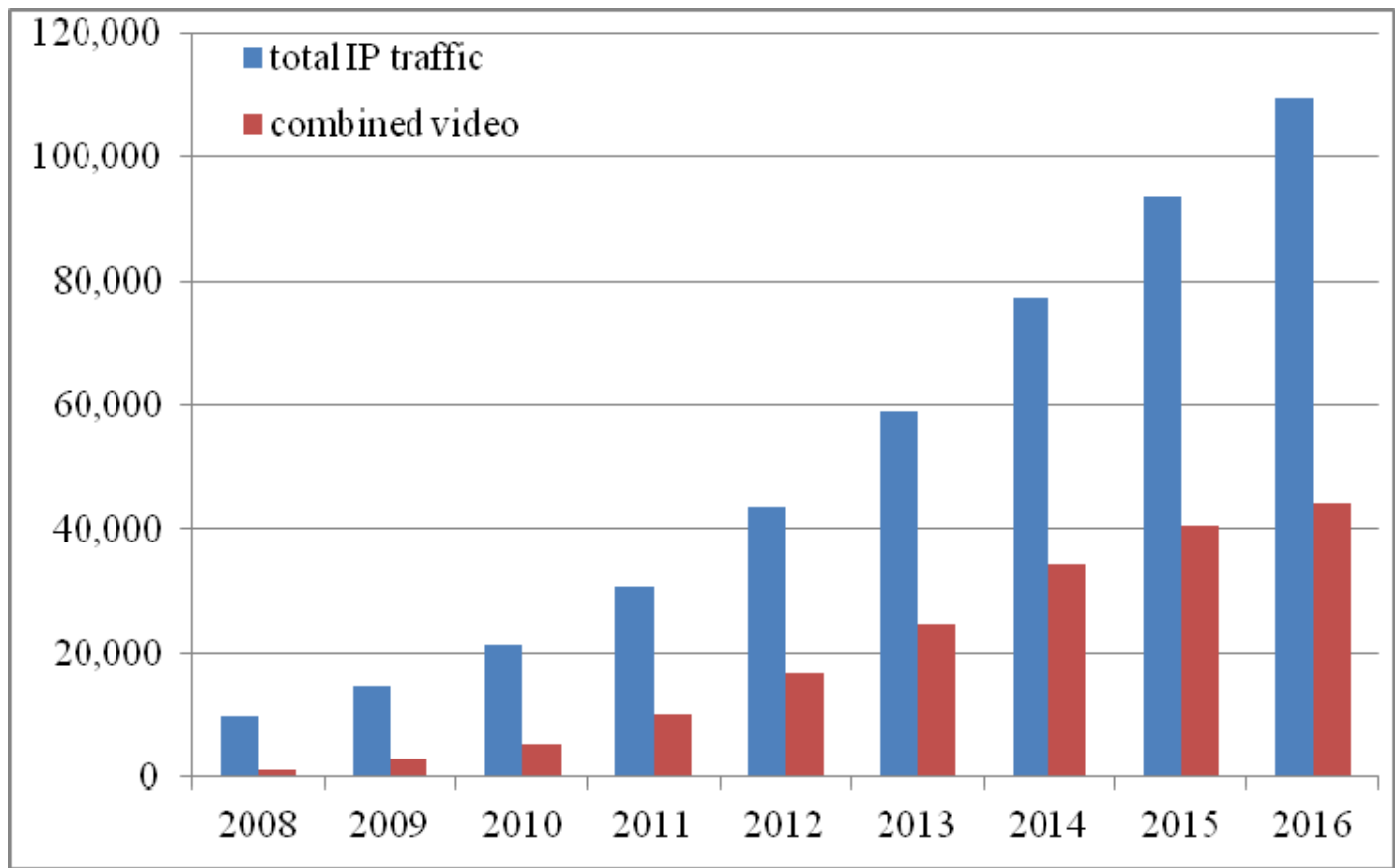

Figure 1. Monthly internet video traffic trend vs. total IP traffic, in petabytes/month

Source: Cisco VNI, May 2012. $\mathrm{PB}=$ petabytes/per second. One petabytes $=1,000,000$ gigabytes. http://www.cisco.com/en/US/solutions/collateral/ns341/ns525/ns537/ns705/ns827/white_paper_c11-481360_ns827_ Networking_Solutions_White_Paper.html

\subsection{Review of Literature}

Americans in 2012 spent more money watching movies at home than they did the previous year, to $\$ 18$ billion. For years, movie business executives have hoped that new ways to download and stream movies from the Internet would make up for declining interest in watching them on disks. The rapidly growing number of televisions connected to the Internet and the widespread adoption of tablets and smartphones give consumers reason to buy or rent from Netflix Inc., Apple Inc.'s iTunes and Amazon.com Inc., and many others in the recent year. In 2012, spending on DVD subscriptions dropped 28\%, while the growth of kiosk rentals was $16 \%$ compared with $31 \%$ in 2011 , according to the Digital Entertainment Group, an industry trade association. Meanwhile, more profitable digital movie purchases shot up 35\%, more than triple the growth rate of the category in 2011 (Fritz, 2013). The transition to digital media content is evidential today as reports reveal that online movie sales at Netflix, the largest movie rental company, exceeded physical DVD disks (Netflix, 2013). The digital copies of movies are expected to increase to 3.4 billion views or transactions in 2012 (i.e. rentals or complete purchases). That's approximately 1.0 billion units more than the predicted 2.4 billion payments for physical DVD or Blu-ray disc copies for the year (King, 2012). Movie stream does not only challenge the traditional way of seeing movies in the theaters, but also impact the traditional movie rental business. The traditional video tape and disk rental company Blockbuster went bankruptcy, while Netflix emerged as the largest web DVD disk rental company a few years ago experienced its stock plummeted from $\$ 269$ a share to $\$ 56$ a share, a more than 75\% drop in September 2012, and rebounded to $\$ 189$ in January 2013 thanks for its movie stream business model (Netflix, 2013, Woo and Sherr, 2012, Rubin, 2012, and Savitz, 2010). Netflix and its competitors use websites where customers can rent for a flat monthly fee, and their e-commerce model has its inadequacy since it was initiated. This is due to the fact that, as part of the process, it is still handled by a traditional delivery system (mail) which may take days for the DVD disks to show up at customers' mailboxes (Vascellaro, 2010, Bilton, 2010, and Lang, 2012). Figure 2 shows the revenue trends between movie stream and DVD rental in Netflix' domestic market. 


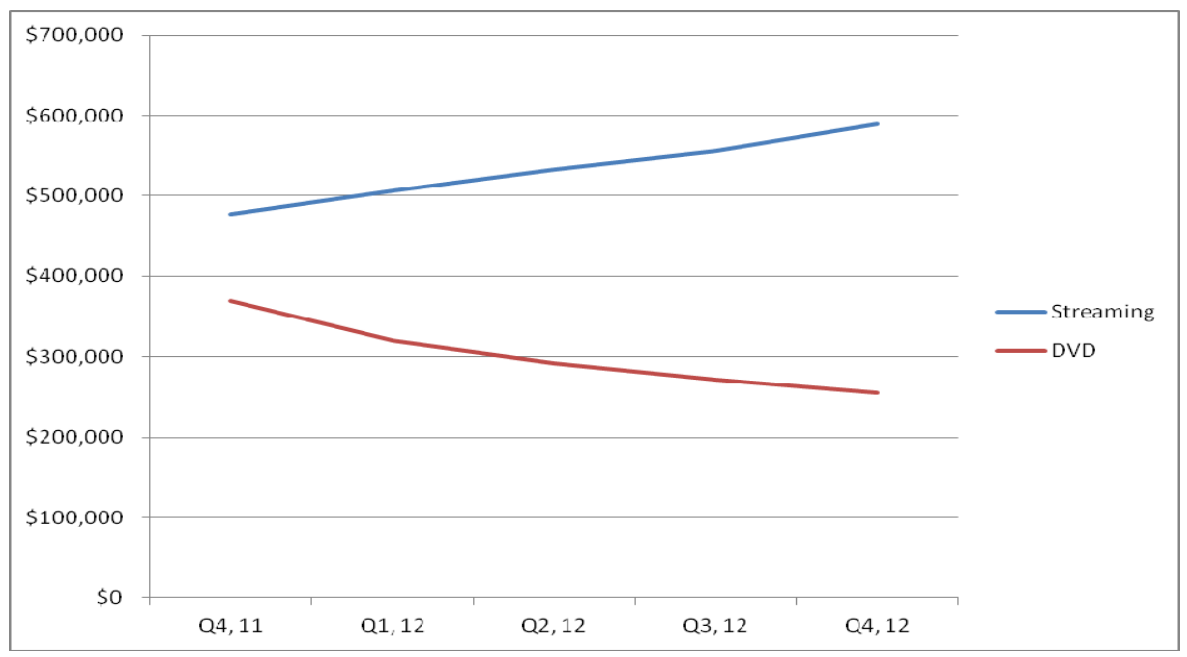

Figure 2. Revenue trends between streaming vs. DVD in the U.S., Netflix

Source: the company, 2013. http://ir.netflix.com/results.cfm

While the traditional movie rental giants, Blockbuster, Movie Gallery, and Hollywood were able to generate billions of dollars in revenues in the past, these companies, on the other hand, are losing ground to more totally internet based movie rental firms of Netflix, Apple, and Amazon.com. Netflix has 27 million streaming customers, as it lets its customer to pay only $\$ 7.99$ a month to search by title or type, then add those titles to a waiting list of movies to watch called a "queue", with no due dates, nor late fees, while ships to most locations by first class mail the next day or stream these movies (Netflix, 2013).

Many traditional cable companies, i.e. Comcast, Time Warner Cable, and the like are going on the offensive. Long technology laggards, the cable companies have set up skunk works. The aim of doing so is twofold: putting more of their content online and making the regular television and movie viewing experience more Weblike. Even as they move online, the cable companies are scrambling to make TV as interactive as the Web. Now the industry may have a hit. It's called tru2way, a service arriving in the coming months that will allow viewers who have the latest generation of set-top boxes and televisions to more easily search for TV shows, play games, chat, and even browse the Web. Beyond improving the viewing experience, the technology also will allow the cable companies to offer interactive commercials. For example, viewers are able to request more information about a sponsor's product and, at some point, even buy it through their televisions (Lowry, 2009). Some issues the movie industry face are described below.

Chao and Li had a study on movie download vs movie rental (Chao \& $\mathrm{Li}, 2010$ ). Their study missed in large the movie stream, as stream had just started, and was less popular given the inadequacy of speed in networking and computers. Some critical issues, i.e. copyright movie sharing were not studied.

\subsection{Piracy, Price, Quality, and Delivery}

The convenience of streaming movies from internet has caused some concerns from the movie makers, as untold thousands of people watched a version of "X-Men Origins: Wolverine" online in early April 2009, a full month before its scheduled theater release, while the film's distributor, 20th Century Fox, said it did not know how the unfinished copy of the comic book adaptation was leaked onto the Internet. Even the copy was missing many special effects and included temporary sound and music, and it circulated widely online beginning on April 1, 2009, even prompting some viewers to publish reviews, favorable and unfavorable, of the hotly anticipated film (Stelter, 2009).

The cost of movie stream varies, depending on the internet service providers' fees. Netflix charges subscribers a flat fee of \$7.99 a month with unlimited movies. Amazon.com matches this price. Many movie streamers have found that in many ways, stream HD movie still cost more than renting DVD disks. Google's purchase of YouTube gave Google an instant access in the video business (Google, 2006). Some factors affect movie stream pricing can be summarized in the following manners: (1) Piracy (leakage) that violates the intellectual property right, would make the movie industry hesitate to put movie online for streaming; (2) Competition that forces the ISPs to cut and/or increases prices depending on market conditions and how many providers in the fields, i.e. Netflix, Walmart, etc; (3) Broadband roll-out (market) that those backbone infrastructure providers, i.e. Cisco, Verizon, Time Warner, etc.

With numerous online video platforms on the market, choosing a solution has become more difficult. Some offerings focus on content management and monetization, while others are geared towards enabling syndication and interactive 
advertising campaigns. For an entire industry that defines itself based on the word "quality", today there is still no agreed upon standard for what classifies HD quality video on the web. Both Microsoft and Adobe have different views on what classifies a video as HD. If the industry wants to progress with HD quality video, some universal standards are needed (GigaOM Daily Feed, 2009).

The traditional mail delivery system usually takes 3-7 days to have the DVD disks show up in the customers' mail box. Netflix's streaming video is content sent in compressed form over the Internet and displayed by the viewer in real time. This technology revolutionizes the delivery (Netflix, 2013), as streamed movies can be watch instantly thanks to the high speed network, while downloading enables customers to obtain movies to their gadgets or computers, and watch them later.

\subsection{Urgent Need for Studying Movie Stream}

As movie stream is emerging as a formidable phenomenon, many interesting questions from both academia and practitioners remain to be answered (Stelter, 2013). This study intends to examine a limited number of the users' preferences, hopefully to provide some managerial insights for home entertainment industry: what consumers prefer and how they make purchasing decisions with a focus on the issues of movie stream vs. DVD rental. In addition, this study attempts through an empirical exploration to investigate if there were any significant differences resulted from the consumers' viewpoints between movie stream and DVD rental, centering on products and their qualities, price (including promotions), deliveries, and usability.

\section{Method}

With the focal questions in mind, this research studied the views of consumers with regards to how they stream movies as compared to DVD rental. A survey was developed to investigate the consumer preferences on products and their quality, price and promotion, deliveries, together with other features available using either movie stream or DVD rental. The following variables were based on literature reviews.

\subsection{Variable Selection}

The following variable selections affect how and where consumers make their purchase decisions. These are incorporated into a survey questionnaire.
1). easy to obtain movies
2). attractive prices
3). easy to watch
4). high definition movies
5). can be easily carried around
6). high sound quality
7). can be easily shared with others
8). no need to buy additional special gadgets or instruments
9). easy and free delivery
10). format can be played on any instrument
11). no concern of copyright

\subsection{Hypotheses}

The hypotheses for this research are to find if there are significant differences between movie stream and DVD rental. The hypotheses for this study state:

Hypothesis 1. There is no significant difference in obtaining movies between movie stream and DVD rental.

Hypothesis 2. There is no significant difference in attractive prices between movie streaming and DVD rental.

Hypothesis 3. There is no significant difference in easiness of watching movies between movie streaming and DVD rental.

Hypothesis 4. There is no significant difference in high definition movies between movie streaming and DVD rental.

Hypothesis 5. There is no significant difference in easiness for carrying movies around between streaming and DVD rental. 
Hypothesis 6. There is no significant difference in high sound quality between streaming and DVD rental.

Hypothesis 7. There is no significant difference in easiness for sharing movies with others between streaming and DVD rental.

Hypothesis 8. There is no significant difference in requirements for buying additional special gadgets or instruments between streaming and DVD rental.

Hypothesis 9. There is no significant difference in easiness and not cost for movie delivery between streaming and DVD rental.

Hypothesis 10. There is no significant difference in movie formats that can be played on any instrument between streaming and DVD rental.

Hypothesis 11. There is no significant difference in concerning of movie copyrights between streaming and DVD rental.

The alternative hypotheses stated: there are significant differences on these variable between movie streaming and DVD rental.

\subsection{Survey and Tests of Hypotheses}

Due to the nature of this empirical study, the questionnaires were distributed to respondents at a couple of large university campuses in the northeast America for a convenient sampling since these respondents tend to browse on the websites and stream movies, and rent DVD disks. The respondents were asked to evaluate the selected variables using a five point Likert scale, with $5=$ strongly prefer, $4=$ prefer, $3=$ neutral, $2=$ not prefer, and $1=$ least prefer.

When two samples are involved and the values for each sample are collected from the same individuals (that is, each individual gives two values, one for each of the two categories), or the samples come from matched pairs of individuals, a paired-samples $t$-Test is an appropriate statistic to use. The paired samples $t$-Test can be used to determine if two means are different from each other when the two samples that the means are based on were taken from the matched individuals or the same individuals. The paired samples $t$-Test compares the means of two variables. This procedure computes the difference between the two variables for each case, and tests to see if the average difference is significantly different from zero, under the assumption of both variables should be normally distributed. The nulls should be rejected if the significance level is less than or equal to five percent in these criteria, in another word, five percent of the paired sample $t$-Test two-tailed probability level signifies the differences in effectiveness between movie stream and DVD rental (Hamburg, 1977; Davis \& Cosenza, 1985).

\section{Results}

612 consumers were distributed, with 272 completed and usable responses for analysis that represents 44.4 percent of the total surveyed. Table 1 presents the general information of the respondents.

\subsection{Backgrounds of the Respondents}

Table 1. Backgrounds of the respondents

\begin{tabular}{lcc}
\hline Variables & Groups & Valid \% \\
\hline 1. Age & $<18$ & 0.7 \\
& $18-35$ & 97.8 \\
2. Gender & $36-55$ & 1.5 \\
& Male & 57.7 \\
3. Family annual income & Female & 42.6 \\
& $<\$ 30 \mathrm{k}$ & 21.9 \\
& $\$ 30-50 \mathrm{k}$ & 17.1 \\
& $\$ 50-75 \mathrm{k}$ & 22.3 \\
4. Educational level & $>\$ 75 \mathrm{k}$ & 38.7 \\
& High school & 13.3 \\
& College & 75.9 \\
5. Marital Status & Graduate & 10.7 \\
& Married & 28.3 \\
& Single & 71.7 \\
\hline
\end{tabular}

Source: original. 


\subsection{Movie Experience}

Table 2 below presents the respondents' pattern of seeing movie. The study indicates that nearly all respondents have access to for their movie watching.

Table 2. The respondents' movie experience

\begin{tabular}{lcc}
\hline Variables & Experience & Valid \% \\
\hline 6a. Have you ever streamed a movie? & Yes & 88.6 \\
& No & 11.4 \\
6b. Have you ever used any special gadget(s) that let you & Yes & 33.1 \\
watch movie, i.e. smart phones, tablets, etc.? & No & 66.9 \\
7a. Movies seen in theaters/month & 0 & 3.3 \\
& 1 & 46.0 \\
7b. Movies watched not in theater/month & 2 & 32.4 \\
& $\geq 3$ & 18.4 \\
& 0 & 0.4 \\
& 1 & 44.3 \\
& 2 & 26.6 \\
\hline
\end{tabular}

Source: original.

Table 3 presents the paired samples $t$-Test results with paired mean differences, standard deviations, $t$ values, degrees of freedoms, the significance levels.

3.3 Results of Paired Samples $t$-Tests

Table 3. The paired samples $t$-Test (2-tailed)

\begin{tabular}{lccccc}
\hline Variables & Paired & Std. & & & \\
mean diff & Deviation & $t$ & df & Sig. \\
\hline easy to obtain movies & $\mathbf{0 . 3 2 1}$ & $\mathbf{1 . 3 4 3}$ & $\mathbf{3 . 9 3 5}$ & $\mathbf{2 7 0}$ & $\mathbf{0 . 0 0 0}$ \\
attractive prices & $\mathbf{0 . 6 1 5}$ & $\mathbf{1 . 2 8 2}$ & $\mathbf{7 . 8 8 2}$ & $\mathbf{2 6 9}$ & $\mathbf{0 . 0 0 0}$ \\
easy to watch & $\mathbf{- 0 . 3 2 1}$ & $\mathbf{1 . 4 1 2}$ & $\mathbf{- 3 . 7 2 0}$ & $\mathbf{2 6 7}$ & $\mathbf{0 . 0 0 0}$ \\
high definition movies & 0.056 & 1.316 & 0.695 & 268 & 0.488 \\
can be easily carried around & $\mathbf{0 . 8 3 5}$ & $\mathbf{1 . 3 9 0}$ & $\mathbf{9 . 9 0 2}$ & $\mathbf{2 7 1}$ & $\mathbf{0 . 0 0 0}$ \\
high sound quality & -0.037 & 1.450 & -0.418 & 271 & 0.676 \\
can be easily shared with others & $\mathbf{0 . 4 3 1}$ & $\mathbf{1 . 3 4 7}$ & $\mathbf{5 . 2 5 2}$ & $\mathbf{2 6 8}$ & $\mathbf{0 . 0 0 0}$ \\
no need to buy additional special gadgets or & & & & & \\
instruments & $\mathbf{0 . 2 3 0}$ & $\mathbf{1 . 2 7 9}$ & $\mathbf{2 . 9 5 1}$ & $\mathbf{2 6 9}$ & $\mathbf{0 . 0 0 3}$ \\
easy and free delivery & $\mathbf{0 . 3 2 3}$ & $\mathbf{1 . 3 2 5}$ & $\mathbf{4 . 0 0 2}$ & $\mathbf{2 6 8}$ & $\mathbf{0 . 0 0 0}$ \\
format can be played on any instrument & $\mathbf{0 . 3 1 1}$ & $\mathbf{1 . 1 8 8}$ & $\mathbf{4 . 3 0 2}$ & $\mathbf{2 6 9}$ & $\mathbf{0 . 0 0 0}$ \\
no concern of copyright & 0.048 & 1.083 & 0.732 & 268 & 0.465 \\
\hline
\end{tabular}

Source: original. Variables in bold indicate significance levels $\leq 5 \%$.

The paired sample $t$-Test results indicate significant differences exist in eight out of the total eleven variables: easy to obtain movies, attractive prices, easy to watch, can be easily carried around, can be easily shared with others, easy and free delivery, format can be played on any instrument, and no need to buy additional special gadgets or instruments. The respondents favor stream against DVD rental over all variables, except easy to watch. Consequently, the variable related null hypotheses are rejected as the significance levels are less than or equal to $5 \%$.

There are no significant differences in three variables: no concern of copyright; high definition movies, and high sound quality. Consequently, the variable related null hypotheses are accepted as the significance levels are more than $5 \%$.

\section{Discussion}

Our survey concludes movie stream is favored by the respondents in easy to obtain movies, attractive prices, can be easily carried around, can be easily shared with others, easy and free delivery, format can be played on any 
instrument, and no need to buy additional special gadgets or instruments. While the respondents favor DVD movie watching as it is easy to watch.

The respondents' favored areas may tell movie industry should continuously focus on these issues. Particularly, movie industry should make movie stream easy to watch, as some respondents indicated, i.e. functions of forward or backward, or search were still lacking.

Not surprisingly, the respondents do not view movie quality significantly differently, i.e. high definition and sound quality, as they believe they would obtain the same quality either from DVD disks or streamed movies.

\subsection{Managerial Implications and Recommendations}

Movie stream presents tremendous growth and can result in substantial reduction in delivery and handling costs, enable the providers to better control the movie products. Meanwhile, online video advertisement spending has increased from $\$ 10.9$ million in 2007 to a predicted $\$ 1.5$ billion in 2012, for a compound annual growth rate of $167.8 \%$ (Marketingcharts, 2012). Movie industry needs to take advantage of this growth and prepare for its own future growth. Intel recently announced that it will join others, such as Apple Inc., Microsoft Corp. and Google Inc. and many movie studios, to offer a selection of live and on-demand TV programming (Clark, 2013). This will make the movie and TV streaming better compete with other ways of viewing movies, ultimately, consumers will be benefited.

\subsection{Limitations and Future Research}

This research, as it surveyed only a small sample, mostly college students, it has several limitations. First, technology advancement will enable movie stream more feasible, as the capability of Internet will be expanded and the computers and networks will be greatly enhanced, the time required for streaming a high definition movie will be greatly reduced. However, this may take some years.

Second, the sample size is small and the representation of respondents is narrow, cautions must be made when one tries to generalize the outcome of the research. The consumers from other segments, rather than college students may present different views about obtaining movie in different ways.

Third, although the key issues of product, price, promotions, and delivery discussed, they mainly focus on the limited number of big players in the market place, i.e. Netflix, Amazon, Hulu, Google, and Apple, many players are left out, i.e. Tudou, etc, not to speak of numerous small and emerged companies with relatively new business models.

Despite these limitations, as investigators, we believe this study may throw some lights for more in depth and broader future studies.

\section{References}

Bilton, N. (2010). YouTube Dominates Online Video Views. NY Times, June 1.

Chao, C. N., \& Li, T. (2010). Movie Download Challenges Traditional Movie Rental. International Journal of Business, Marketing, and Decision Sciences, 3(2), 78-87.

Cisco. (2012). VNI report, May. Retrieved from http://www.cisco.com/en/US/solutions/collateral/ns341/ns525/ns537/ns705/ns827/white_paper_c11-481360_ns 827_Networking_Solutions_White_Paper.html

Clark, D. (2013). Intel to Launch Web TV Service This Year. The Wall Street Journal, February 12.

Conover, W. J. (1980). Practical Nonparametric Statistics (2nd ed.). New York: John Wiley \& Sons, pp. 213-337, 344-384.

Davis, D., \& Cosenza, R. M. (1985). Business Research for Decision Making. Boston, Kent Publishing Company.

Fritz, B. (2013). Home video revenue stops falling. LA Times, January 08.

GigaOM Daily Feed. (2009). Media \& Entertainment, News, Broadcast \& Cable. March 23.

Google. (2006). Retrieved from http://www.google.com/intl/en/press/pressrel/google_youtube.html

Hamburg, M. (1977). Statistical Analysis for Decision Making (2nd ed.). Harcourt Brace Jovanovich, Inc., New York, pp. 219-538.

King, R. (2012). Americans will pay more for online videos over discs in 2012. Between the Lines, ZDNet, March 22.

Lang, B. (2012). DVD and Blu-Ray Rental Market Plummets 21.3\% in Q4. CNN Money, March 26.

Lowry, T. (2009). Cable TV: Pushing to Become More Web-like. Business Week, April 2. 
Netflix. (2013). Retrieved from the company, http://ir.netflix.com/results.cfm

Retrieved from http://en.wikipedia.org/wiki/Kruskal\%E2\%80\%93Wallis_one-way_analysis_of_variance

Retrieved from http://www.marketingcharts.com/direct/local-online-video-advertising-to-soar-reach-15b-in-2012-5058/kelseygroup-local-video-ad-revenue-forecast-us-2007-2012jpg/

Rubin, B. F. (2012). Netflix Video Streaming Totaled Two Billion Hours. The Wall Street Journal, January 4.

Savitz, E. (2010). Blockbuster Chapter 11 Filing Drawing Near, Barron's and the Wall Street Journal, September 22.

Stelter, B. (2009). Piracy Puts Film Online One Month Before Open. NY Times, April 2.

Stelter, B. (2013). New Way to Deliver a Drama: All 13 Episodes in One Sitting. NY Times, January 31.

Stone, B. (2010). Wal-Mart Adds Its Clout to Movie Streaming. NY Times, February 23.

Vascellaro, J. E. (2010). YouTube to Test Video Rental. The Wall Street Journal, January 20.

Wingfield, N. (2010). Coming Attraction: Netflix on the iPad. The Wall Street Journal, April 1.

Woo, S., \& Sherr, I. (2012). Netflix's Growth Disappoints. The Wall Street Journal, April 23. 